\title{
Creative Meanings within the Context of an Advertising Campaign
}

\section{Asdrúbal Borges FormigaSobrinho, University of Brasília, Brazil}

\begin{abstract}
This article approaches the cultural psychology to interpret the semiosis of a concept used within the communication of an organization by considering the interactions among persons and culture mediated by a creative product. It deals with the creative potential from the dialogical style of lay thinking in the generation of new meanings. As lay thinking and social creativity are concepts related with the social representations theory, the article considers social representations as potential constraints to semiosis processes. The interpretation of the campaign argument is based on concepts such as text, from the culture semiotics in the molds of the Russian features, and it occurs from the approach to the non-text or narrative contrary to the campaign description. The results show the ambiguous creative action of resignificance of a concept within the external organizational context and consequent actions for its adaptation features.
\end{abstract}

Keywords: Culture, creativity, institutional image, text, meanings. 


\section{Introduction: meanings of creativities}

In our culture, creativity is a seductive term that is quite associated with originality and relating both to inventions and to the establishment of new relationships (Novaes, 1972; Wagoner, 2010) among codes, for example.

Regarding the first aspect, the term is associated with the creative person and product, but cannot " "stand apart' from their social background" (Gläveanu, 2010, p. 148) cause itinvolves people's positioning, understood as "the discursive process in which people are located in communications as participants who are observably and subjectively in messages that are jointly produced" (Davies and Harre, 1997, p. 46). Thus, it comprehendsfrom knowledge to the emotional and moral attitudes of the participants in the creative process, including for the second item the semiosis, understood as "a process of transformation and transmission of messages" (Machado, 2003, p. 52) whose outcome may lead people to understand or even develop contentsin a different way.

The comprehension or response to the creative message also involves values that are based in the human condition (Bain, Kashima and Haslam, 2006) and are culturally shared. Such cultural trait contributes for the definition of values, also by the impact of emotions over beliefs, which originate from knowledge and religious practices (Weber, 1998), and constitute true "rules for actions" (Rosa, 2007, p. 311) whose diversity or interpretation may diversify demeanor based on emotions that add importance to meanings.

A different approach can be found at Magioglou (2010), who considers the role of lay thinking, concept related with the common sense from the theory of social representations (Moscovici, 1961) and contradictory due to its relation with the creative process, as we mention in a session below. However, the process involved by lay thinking can be also related to the dialogical (Bakhtin, 2006) creative process of meanings (Valsiner, 2007), which takes place in specifics cultural, social and historical contexts of individual and social interaction and can diversify the possibilities of new actions like dialogues or others.

In this article we consider both cultural and social approaches to deal with the creativity and the creative person categorization as a result of contradictory comprehensions of the same discourse in relation with familiar categorizations, cause "If one text doesn't remember one 
traditional construction, its innovative character cannot be noted.(Lotman, 1978, p. 57)". In the same way, "For the theory of social representations, social creativity is the ability of groups to elaborate objects coming from outside of what is known and communicated within their group."(Wagoner, 2010, p. 469). As an initial consequence of the statements, we can ask where or how to find creativity in a text or in an actioncorrelated.

Besides the association to the new and to the person that is considered creative, the term creativity is also related to the process of creation and to the created product (Novaes, 1972), and we intend to reach both by:the approach of semiosis or ressignification of an advertising message as interaction effect to different audiences; and the discussion of creative qualification in both poles from the interpretation of its attitudes and attenuating/generating actions of a crisis triggered by the interpretation of a certain "organizational speech" (Halliday, 2009, p.46). Such interpretation is initially based on the fact that most professionals responsible for the development of institutional campaign and their classification as creative defined and created products are expected and even demanded from them; and in our intent to show other sides of classification applied to them and to ponder components of the communicative process described below.

However, we mention the possible stereotyping of the creative person, since it is possible "to be creative through an internal process which is continuously active and not always observable, yet fundamentally unobserved and not identified as such in certain cases."(Novaes, 1972, p. 33). Besides, even though the presentation of innovation or originality tends to interfere with the status quo components, being creative is not always a synonym of being subversive, first because the person produce messages in cultural or subcultural contexts (Gläveanu, 2010) and second because the creative minds may also produce messages that are consonant with the status quo or contradict it, rethink strategies and consider that the negotiation, especially those related to meanings depends on multiple contextual factors that will be presented in the following sessions.

\section{An approach to dialogical creativities}

In this session, we approach creativity applied to the organizational rhetoric and expressed in an advertisement, based on an interpretative perspective, which approaches the organizational culture as a network of meanings (Kunsch, 2009) in order to deal with the semiosis of a 
communication concept.The approach originates from the following research question:although it is possible to make better use of communication resources and monitore the reception of organizational speeches within the external (Iasbeck, 2009) or internal (Roman, 2009) scope, would there be sufficient creativity or strategic sense to control and institutional image or would it simply be a goal?

The audiences concept of image of an organization from pre-existing models and a progressive construction which is also guided by communication and, in our example, by advertisement.Such language under performs an important role in the production of speeches herein named texts (Lotman, 1978), for the fact it involves verbal and visual codes that intend to control as they continually rebuild identities.This occurs because according to the conception of Hall (1992), individuals have multiple identities that are related to different factors such as social class, gender, occupation, etc.; and such multiplicity also applies to organizational identities since the advertisement in general communication seek to personify organizations and transfer their positioning according to the fact that identities must be constructed, acknowledged and notified in incorrect intentions, not only in linguistic ones among subjects.

However, certain tensions do not appear only within the inter-organizational scope.As an example, we will approach the reaction to the release of a campaign based on the concept Decide for Three, signed by the Bank Beta (fictious name).The main script of the advertisement piece is presented here.

Soundtrack Rock with guitar riffs in slower rhythm.

(BG):

Narration In the beginning, it was decided that it would be round and it was decided in off: that it would have firm land and blue skies with white clouds during the day, it was also decided that it would have water and that it would be in the seas and rivers. It was decided that it would have air and winds. It was decided that would have plants and animals. It was decided that the fish would be in the water and the birds in the skies. It was decided that there would be people and we would depend on all of that to live. So, it was decided that from now on we would make the decisions. There were 
different opinions and each one made his decisions. There were people who decided to navigate the seas. There were people who decided to fly the skies. There were those who decided to conquer the space. Some decided to be leaders, and their important decisions changed the world. Sometimes for worse, sometimes for better. And since these decisions took so much from us, it took us a while to realize that they can decide our future. And so we decided to do something to take care of all that is being decided or will be decided from now on.

Image: Several pictures of the following scenes. Part of the planet spinning with the sunlight in the background. Volcanic eruption. Fire. Forest with dinosaurs and comet. Mountains rapidly passing by. Earth. Forest. Sky with clouds. Great waves. Amazon River. Dark and cloudy sky. Leave falling in water. Buds sprouting. A jaguar resting the top of a tree. Blue and yellow fish swimming. Seagulls flying in the sunset. Woman at the beach. Smiling black man with a Rastafarian haircut. Girl with skies and clouds in the background. DNA Chain. Large tree in a field. Images succeeding accelerated cities, airplanes, planet, man opening a door in the dark. Man with a question mark on the background. Three men having fun and singing. Woman with a picture that qualifies parts of the brains and her possible thoughts. Three smiling children. Friends (black, blonde and brunette) embracing. Caravels. First airplanes making acrobatic moves. Astronauts and rockets. Man with megaphone. Black and white pictures with warplanes, human beings, a surprised boy and marching soldiers. Scenes of bombs, natural accidents and cataclysms, factory smoke. Scenes of the Berlin Wall fall. Faces of Gandhi and Betinho. A drawn rose. Image of a TV set. Old person in a field. Children in a classroom learning about dinosaurs. City growing. Child holding an animal, demonstrating care. Couple dating. Picture of a pregnant woman, marriage.

Narration We have decided for three and we want to invite you to make this in off: decision with us. It means having at least three attitudes a day, thinking about the sustainability of the planet. It may be turning off the light, closing the tap and teaching someone. Three. It may be planting a tree, 
picking up a can from the ground and acting with ethics. Three. It may be taking a shorter shower, respecting differences and using the stairway. Three. Only three. Everywhere you see this number, you will know that there is a way for you to make the decision to take care of the planet, the people and the country we live in. Three.

Image: Young man showing three fingers. Scenes of children from different ethnic backgrounds. Man in a wheelchair. Beach with the number tree written in the sand. Man holding watering can. Hand with object that resembles the planet. Lamp. Tap. Woman showing the number three with her hands and smiling. Child picking up a can from the floor and tossing it in the garbage bin. Person walking on a line. Children in a ladder that show number three. Black man and the image of water drops going up. People walking with work clothes. Child climbing a tree. Woman showing number three. Vane. Number three. Man that makes a decision and happily crosses a line drawn on the floor. Earth. People smiling, seemingly happy. Three eggs on the nest. Baby. Three nurses from different ethnic backgrounds. Smiling young person. Three children playing. Oriental boy. Three friends walking and embracing.

Lettering: bankbeta.com.br/sustentabilidade and get to know the Agenda 21 with a blue background.

Agenda 21. 2+1=3. The letters are yellow. (color of Bank Beta).

Narration For the future of our planet and rely on the Bank.

in off:

Lettering: All yours.

Image: Federal Government Brands.

The announcer is an important state organization that uses communication in a way to legitimize itself in the salary of power of the government and the aforementioned advertisement is a way to confirm that "good communication means presenting good reasons for past, present and future acts and events" (Halliday, 2009, p. 46). In the plot, it occurs when we deal with the history of the earth and humanity and what can be made now to ensure a better future - or even any future at an implicit level - for the human species and for the planet. It is an argument that deals with religious themes related to creation and based on 
principles of remote religious propaganda (Domenach, 1955) that are also used in marketing, but with the difference that the religious one promises a better life somewhere else and the marketing promises a better life on Earth.Intermediately we find the institutional advertising, whose example is summarized in the concept of Decide For Three values and beliefs of the audience and organizational goals related to various actions and programs such as the Regional Sustainable Development oriented towards activities such as agriculture and handicraft.

The aforementioned institutional advertisement takes on a creative characteristic, for initially basing its rhetorical in feelings and emotions (Novaes, 1972) and transcends the mere informative characteristic in process of "culturalization" (Machado, 2003, p. 142) experienced by different poles of communication.This occurs because what generates and differentiates the individual, the process and the creative product is its biography, that means the importance of the individual as a constituent and constitutive of culture (Valsiner, 2007; Velho, 2004) and, as previously mentioned, the same applies to personified organizations when dealing with identities. Moreover, when we give importance to the creative individual and its interactions with other individuals, creative products, creative processes and the cultures or some of its features, we reach the "cultural psychology of creativity"(Gläveanu, 2010, p. 153) approach, which deals with the culture not only as a constraint power over individuals and their communication and gives us basis to deal with messages creation, reception and recreation.

The advertisement message contradicts a prevailing trend in corporate communication and it is also addressed by Iasbeck (2009) when explaining its purpose and encouraging interaction.Thus, in a first level of comprehension, it can be considered creative, cause “"contradictions' and 'inconsistencies' constitute the key elements of the creative dimension of lay thinking." (Magioglou, 2010, p. 447) and the advertisement seeks to dialogue with most of the Brazilian population. Perhaps this creative character occurs due to the fact that the advertisement lease is signed by a state organization, even though it competes with private companies within the same category, at similar levels of investments not only in communication. Such competition may have contributed to the approach of things such as those related to social-environmental responsibility that have been part of the institutional gender for quite long time and mixed with those resources normally used in market, 
especially by organizations that need institutional advertisement to correct their images (Gracioso, 1995) and provide results to the society, such as financial ones.

In this sense, the institutional gender is also blended with the marketing, which is explicitly persuasive for commercial purposes and whose rhetoric has permeated the most different kinds of persuasive speech (Reboul, 1996) and has resorted to "acts of social responsibility that became necessary for the maintenance of thestatus of persona gratasought by organizations."(Halliday, 2009, p. 35). Therefore, specially due to the fact the advertisement may be questioned and validate its dialogical character, it is important to make sure that the audience believes in what is being said and that the statements, even organized in a creative form, are compliant with the values and beliefs they already share or, in other words, are familiar.

And a debate actually resulted from the advertising when theDemocrat Senator for the State of PiauíHeráclito Fortes "took the podium to accuse the government of once again using a public bank to make a subliminal advertising favoring a third term of Pres. LuizInácio Lula da Silva" (ScinoccaandFilho, 2007). While on one hand based on the teaser factor of the advertisement campaign, according to the poster displayed at bus stops in Picture 1 and composed by several illustrated pieces by the concept and especially for the number 3 , including a shirt worn by the then Labor Work Senator for the State of São Paulo Eduardo Suplicy - providing this type of interpretation; on the other hand, the opposition took the opportunity to officialize a rumor that was also commented by the press in 2007.

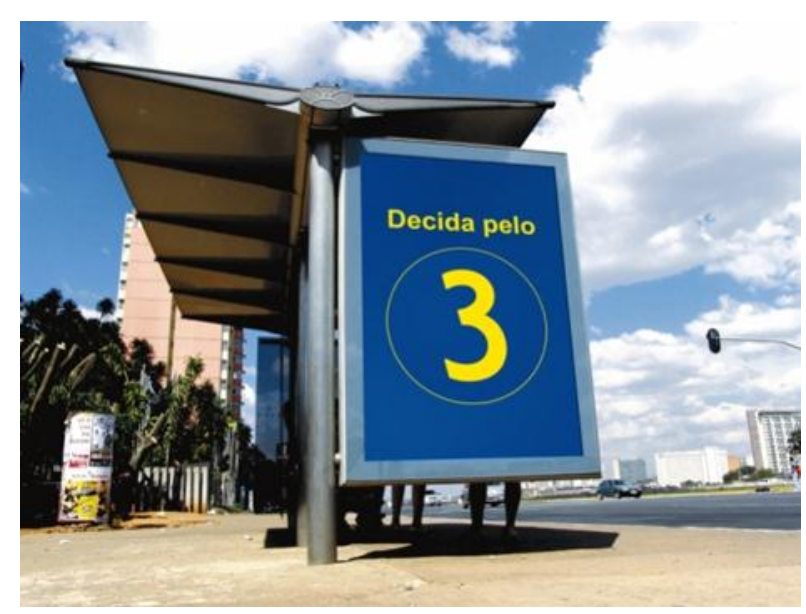

Figure 1.Outdoor medium. 
And so it triggered a crisis that motivated us to approach the subject, for within these contexts institutional image is vulnerable and the communication is necessary to recover, maintain or improve the reputation of the organization.However, the tension was no accidentbut stimulated by the rhetoric of a discourse based on representations of beliefs and values that are socially and historically shared (Moscovici, 2003) and culturally regulated (Machado, 2003), once the President was successfull towards the majority of the population at least under an economic point of view.

On one hand, we do not consider the plot of the advertisement a simple rhetoric that could even make its effects impracticable (Halliday, 2009) or hamper previously defined organizational goals. The campaign also contemplated an internal audience, who approved the actions, especially after receiving an e-mail with the video file of the aforementioned advertisement even before the external audience. On the other hand, we did not have access to information regarding subtle electoral intentions by the advertiser or those creative involved with the production of the advertisement.However, at least - not merely - in the rhetoric of the opposition represented by one individual the advertisement used ambiguities to generate a favorable attitude among the audience, certainly according to their representationsof the governor or familiarity with the possibility of a governmenttry increased by the press and certainly ruled by cultural elements from Brazil and by peculiarities of the organizational culture of the announcer (Kunsch, 2009), leaving us to ponder how the limits found by a text related to it contributed to thesemiosis of the text itself.

\section{Towards limited creativities}

The limit may be understood as a characteristic element of opposition between a text and the signs that do not compose it (Lotman, 1978), herein called non-texts. The limit is defined by marks that characterize the texts from its cultural function or its gender: novel, film, advertisement, etc. basically established as opposed to other structures, with the adult impediment of inter-structural sign exchanges, since the meeting may be changed during the culturalization process and whose "final result is the transformation of a non-text into a text" (Machado, 2003, p. 39).

While we may consider the coercive nature of culture, we also deal with the double modeling of subject and object (Lotman, 1978), which rules and is also ruled by the organizational 
culture. However, here we face a deadlock for an organization ran an advertisement and the representative of another organization, which is the opposition to the government, took the chance to oppose a discourse that, even though consonant with the representations related to the preservation of environment and the human species and social responsibility of banks, opened an opportunity for questioning regarding the relationshipbetween such organization and the management by the Federal Government.

That action could be an example of the importance of ambivalences for the creation of new meanings, once the discourse can become vulnerable towards its reception and "different ideological horizons allow an opening to different forms of thinking” (Magioglou, 2010, p. 447). In this sense, the contradiction in the organizational discourse was intentionally suggested by the opposition, whichmade the ambivalence grow up fast. This result was possible due to the fact that the familiar element performed like unfamiliar (Wagoner, 2010) in the text advertisement and that performance involved questions and answers inherent to lay thinking and different or even contradictory answers to the same question inherent to ambivalences (Magioglou, 2010). Consequently the stronger meaning was the one linked to the familiar context from the journalistic discourse, for example, and shared by the public opinion as a social representation, which reinforced the opposite discourse as non-text, especially by stopping a try of creating new meanings for a concept in what we call a truning back process.

So, who was creative in the story? Initially those responsible for the advertisement.However, though ambiguously due to the return to the familiar meaning, a politician had a creative attitude that:

represents an adequate response to a new situation in a more adequate and constructive response to an old situation, and the creative individual must be able to modify his behavior in response to new information, develop perspectives in order to consistently move ahead by himself in a unique style of learning, encouraging change, providing opportunities for transferring and applying the knowledge to real situations.(Novaes, 1972, p. 48-49)

Besides, the meanings negotiation is essential for the creative process and can result from ways of dealing with ambivalences, although considering that the creative product can also be 
a new relation between things or a new way of comprehension which does not change deeply some meaning.In the interpreted situation we could consider something not like "creativity of lay thinking" or "societal creativity" (Magioglou, 2010, p. 446), but just like a way of manipulating meanings, cause the fact that "managing the dynamics of these relations [among different audiences] means to be alert to possibilities that constantly open and close the systemic flow of informational exchanges."(Iasbeck, 2009, p. 16). Therefore, as a consequence of attitude, its discursive action was validated in the inverted semiosis of the concept of Decidefor Three, whose meaning in discourses of other gender such as the journalistic embarrassed the state banking organization, and it was based on the identification or in the "accreditation of particular traits of each one of the cultures that produce their respective discourses, traits that are interrelated with traits of each culture."(Iasbeck, 2009, p. $18)$.

In other words, the tension involved in the manipulation of the concept contributed to transform the non-text into text by using opposing forces that are initially catalyzers of creativity, which is also understood as a way to solve problems (Novaes, 1972) employed in the rhetoric of the banking organization - with the purpose of solving communication problems as a creative resource of an adverse strategy. At that moment, the opposition discourse was presented as a novelty, a characteristic related to frailty (Roman, 2009), as the ambiguity, which "is but a phase in the movement towards non-ambiguity" (Valsiner, 2003, p. 7.4), in the way it can let the individual to the psychosocial stability (Moscovici, 2003) based on the maintenance, not in the change of meanings.

However, the period and the official and unofficial media for presenting the opposite message were sufficient for modifying the strategy and suspend the campaign whose frailty was provoked by an action that can be considered creative not only for its subversive characteristic regarding the announcer, but adapted in relation to the opposition to the government; its ambiguous similarity with informal communication- it is not enough to be a fact because it was not spontaneously produced -or for its rumor characteristic.Roman (2009), based on Restrepo and Angulo (1992), addresses the last two modalities, with the rumor being efficientbecause "it refers to reality, but has no commitment to it and actually reverts it" (Roman, 2009, p. 134); and it is able to spread rapidly due to be based on the familiar. 
So, the organizational culture of the banking institution was questioned before the public opinion and the discourse of the opposition was characterized as a non-text whose meaning was confirmed in possible extra text connections (Lotman, 1978) within that context and it became victorious before the chance of practically transforming the central campaign message into a threat to democracy.The vulnerability of the organization before the contents of its own communication meets the fourth model of organizational communication of Goodall Jr., Eisenberg, \&Trethewey (2010), which "presents communication from the perspective of balance between creativity and subjection" (Scroferneker, 2006, p. 51) and takes into consideration social interactions and power games.In our approach, the two latest phenomena are ruled by the culture in which the organization negotiates meanings or to promote any change and then be characterized as creative, or for maintenance of the status quo.

Without approaching the basis of accusation issued by the aforementioned politician and duly denied by the President of the Republic in Office, by the announcer and by the advertisement agency; and without considering the possible greater involvement of private interests rather than favorable changes to the population to whom both organizations must present results, the result was favorable to the opposition in that sense of institutional image risk, since the advertisement and the organization positioning was greatly modified.

On the other hand,it can be observed the creativity of those involved with the planning and campaign production, who also changed their positioning,knew how to deal with the ambivalences explored by the other pole of communication,were flexible and, according to the conception of Bueno (2009), were able to search for alternatives to solve unexpected problems and change the strategy before an adverse situation. So it was possible to observe the power of a mere rumor before an organizational discourse (Roman, 2009) and under the perspective of the opposition, as a strategy of expression of positioning and facing managers not only of the organization, but of the federal government as a whole. The opposition action materialized by its discourse, characterized as non-text towards the advertisement, could also be considered creative for it constitutes a space of freedom, questioning of an official discourse and the way the values employed were established.However, the accusation originated old, not new relations between the employed codes. 
On the side of the attacked organization, as a consequence of the text double modeling potential (Lotman, 1978), there was also the "symbolic boundary spanning" (Halliday, 2009, p.40) or "symbolic of organizational borders" which is an adaptation mechanism to maintain the organization in synchronicity with the environments it interacts with (...)"(Idem), also seeking the exchange of meanings between the organization and external context in its own benefit.The managers of the organization and the communication know the cost of losing status for a bank that, just like any other, include social responsibility among its organizational goals, but found limits in this same plurality and in the same tensions that are base of the rhetoric of an advertisement that provides such relevance to the differences among people to reinforce present social representations. Therefore, the limit was the restriction of the intra-organizational creativity by an inter-organizational action, which lead us to consider the potential of representation and of language to create new meanings side by side with their potential to constrain (Wagoner, 2010) and consequently limit people's future experience (Valsiner, 2003).

So, the opportunistic discourse, although inconvenient in relation to the official one, was successful due to the fact it was originated and legitimated in an environment external to the organization, differently from the context approached by Roman (2009).And even though there was some margin for other negotiation of meanings, the way to make it favorable would be complex and the bank did not want to continue that rhetoric measure without at least reviewing it.Such behavior validates the considerations about the fact that the organizational discourse is more oriented towards "fomenting understanding and honoring the implicit fact of reliability between the rhetor and the audiences" (Halliday, 2009, p.46) than for persuasive purposes.However, the aforementioned author herself considers the importance of argumentation in the definition of trust relationships, even though she does not consider the fact that the objectives are not separated not even in institutional advertisement seeking medium and long-term results such as those reflected in this additional image, and also the tangible results such as the number of clients.

Regardless of which was the primary intention of the advertisement, the organization did not want to wait the possible results from the continuity of the opposing action both at the language level and election or politic level; it chose the redirecting of its discourse as an action of repairing, protective or reinvigorating communication of its image. The concept 
Decide for Three, even though it meant to enhance its creativity and its suppliers, it represented risk to the institutional identity for if it is related with identification or empathy, "(...)there is only identity whenever the image harmoniously coexists with the strategic intentions of the institutional discourse.”(Iasbeck, 2009, p. 28).

So, according to the interpretive context, in which the creativity employed in the communication strategy of an organization found limits for the reception of its text and faced as opponent the "co-participation of audiences in the modification of the rhetoric situation" (Halliday, 2009, p.48), there is no sufficient creativity or strategic sense to control an institutional image and such control is simply a goal.If even within the internal scope, which is supposedly easier to manage or control, several organizations face challenges and seek to use communication favorably to their objectives, let alone in the external scope, which takes into consideration the fact that the "language is influenced by those not inherent to it, but to socially organized groups who use it."(Roman, 2009, p. 128).

The questioning once again brings about a cultural trait that rules language and the social interactions correlated within the most different intra-organizational and inter-organizational contexts, thus affecting the organizational culture.And before such character the comprehension of the phenomenon requested a social semiotic approach (Machado, 2003), more oriented to read power to the sense rather than sense to the power or seeking to go beyond the fifth model of organizational communication suggested by Goodall Jr., Eisenberg, \&Trethewey (2010) to approach "organizations as spaces of dialogue" (Scroferneker, 2009) or even tensions, since our example also involved an interorganizational context.It also involved a text of advertisement language that such as the others, mediates several contradictions between organizations in the same category and, in our particular example, between organizations that are quite different on one hand but similar on the other hand - and not always supporting the management of the Federal Government.

\section{Acknowledgements}

This work had the support of the Deanship of Research and Graduate Studies [DPP] at the University of Brasília - UnB. 


\section{References}

Alencar, E.S., \& Fleith, D.S. (2003). Criatividade - múltiplas perspectivas. (3rd ed.) Brasília: Editora UnB.

Angelo, S., Minini, M., \& Molin, R. (2007). Decida pelo Três. [Movie-video]. C. Freire e L. Toaldo, dir. of creation. São Paulo: Margarida Flores e Filmes. DVD/NTSC, 3 min., color.son.

Bain, P.G., Kashima, Y., \&Haslam, Nick. (2006). Conceptual Beliefs about human values and their implications: Human nature beliefs predict value importance, value tradeoffs, and responses to value-laden rhetoric. Journal of Personality, 91(2), 351-367.

Bakhtin, M.M. (2006). Marxismo e filosofia da linguagem (12th ed.) São Paulo: Hucitec.

Bueno, W.C. (2009). A comunicação como inteligência empresarial competitiva. In M. Kunsch (Ed.), Comunicação Organizacional - Vol. 1 (pp. 367-387). São Paulo: Saraiva.

Davies, B. \&Harre, R. (1997).Positioning: The Discursive Production of Selves. Journal for the Theory of Social Behavior, 20(1), 43-63.

Domenach, J.M. (1955). A propaganda política. São Paulo: Difusão Européia do Livro.

Eisenberg, E.M., Goodall Jr., H.L., \&Trethewey, A. (2010).Organizational communication: balancing, creativity and constraint (6th ed.). New York, USA: Bedfor / St Martin's Press.

Gläveanu, V.P. (2010). Principles for a cultural psychology of creativity.Culture \& Psychology, 16(2), 147-163.

Graciososo, F. (1995). Propaganda institucional. Nova arma estratégica da empresa. São Paulo: Atlas.

Hall, S. (1992). A identidade cultural na pós-modernidade. (10th. ed.). Rio de Janeiro: DP\&A.

Halliday, T. L. (2009). Discurso organizacional: uma abordagem retórica. In M. Kunsch (Ed.), Comunicação Organizacional - Vol. 1 (pp. 31-51). São Paulo: Saraiva.

Iasbeck, L.C.A. (2009). Identidade organizacional e a construção dos discursos institucionais. In M. Kunsch (Ed.), Comunicação Organizacional - Vol. 1 (pp. 7-29). São Paulo: Saraiva.

Kunsch, M. (2009). Percursos paradigmáticos e avanços epistemológicos nos estudos da comunicação organizacional. In M. Kunsch (Ed.), Comunicação Organizacional Vol. 1 (pp. 63-89). São Paulo: Saraiva.

Machado, I. (2003). Escola de semiótica. São Paulo: Ateliê Editorial / Fapesp.

Magioglou, T. (2010). The creative dimension of lay thinking in the case of the representation of democracy for greek youth. Culture \& Psychology 14(4), 442-466.

Moscovici, S. (1961). A representação social da psicanálise. Rio de Janeiro: Jorge Zahar.

Moscovici, S. (2003). O fenômeno das representações sociais - Investigações em psicologia social. In S. Moscovici. (Ed.), Representações sociais (2ndEd.) (pp. 29-109.). São Paulo: Vozes.

Novaes, M.E. (1972). Psicologia da criatividade (2. ed.). Petrópolis: Editora Vozes.

Reboul, O. (1996). Introdução à Retórica. Rio de Janeiro: Martins Fontes.

Restrepo, J.M.,\& Angulo, J.R. (1995). Intervenir en la organizacion. Santafé de Bogotá: Significantes de Papel Ediciones, Serie: Comunicacion Organizacional.

Roman, A.R. (2009). Organizações: um universo de discursos bem-ditos, mal-ditos e nãoditos. In M. Kunsch (Ed.), Comunicação Organizacional - Vol. 1 (pp. 125-157). São Paulo: Saraiva. 
Rosa, A. (2007). Dramaturgical actuation and symbolic communication: Or how beliefs make up reality. In J.Valsiner,\& A. Rosa (Eds.).Cambridge Handbook of Socio-cultural Psychology (pp. 293-317).Cambridge: CUP.

Scinocca, A.P.,\& Filho, E. (2007). Heráclito e Suplicy discutem sobre campanha do BB no Senado.O Estado de S. Paulo.Retrieved from http://www.estadao.com.br/noticias/,heraclito-e-suplicy-discutem-sobre-campanhado-bb-no-senado,35438,0.htm

Scroferneker, C.M.A. (2006). Trajetórias teórico-conceituais da Comunicação Organizacional. Famecos, 31, 47-53.

Valsiner, J. (2003). Beyond social representations: A theory of enablement. Papers on Social Representations, 12, 6.1-6.16 (http://www.psr.jku.at/).

Valsiner, J. (2007). Culture in minds and societies: foundations of cultural psychology. New Delhi: Sage Publications.

Velho, G. (2004). Individualismo e cultura (7th ed.). Rio de janeiro: Zahar.

Wagoner, B. (2010). Making the familiar unfamiliar.Culture \& Psychology 14(4), 467-474.

Weber, M. (1998).Economia e sociedade(4. ed.). Brasília: UnB. 